Endocrinol. Japon. 1988, 35 (4), 545-548

\title{
Changes in Prolactin Levels Caused by Luteinizing Hormone Releasing Hormone
}

\author{
Koji KUGU, Yuji TAKETANI and Masahiko MIZUNO \\ Department of Obstetrics and Gynecology, \\ Faculty of Medicine, University of Tokyo \\ 7-3-1, Hongo, Bunkyo-ku, Tokyo, 113, Japan
}

\begin{abstract}
The acute effects of luteinizing hormone releasing hormone (LHRH) on the release of prolactin (PRL) were investigated in 12 normal cycling women and 42 women with various menstrual disorders. LHRH $(100 \mu \mathrm{g})$ was bolusly injected intramuscularly and PRL levels were measured immediately before the injection and at 30 minutes and 60 minutes after the injection. LHRH elicited an increase of more than $25 \%$ in PRL levels in 15 cases $(27.8 \%)$ at both 30 minutes and 60 minutes after the injection, whereas PRL levels were decreased by more than $25 \%$ in 7 cases $(13.0 \%)$. The PRL response to LHRH seemed to be related to basal PRL levels. Especially when the PRL concentration was $20 \mathrm{ng} / \mathrm{ml}$ or more, LHRH decreased PRL levels in 7 cases out of 16 . On the other hand, LHRH increased PRL levels in the majority of cases with a PRL concentration less than $20 \mathrm{ng} / \mathrm{ml}$. In conclusion, the LHRH injection occasionally alters PRL levels in either a positive or negative manner, depending upon the basal PRL levels.
\end{abstract}

The synchronous secretion of luteinizing hormone (LH) and prolactin (PRL) has been observed in both normal cycling women (Bäckström et al., 1982; Braund et al., 1984; Cetel et al., 1985) and hypogonadal women (Cetel et al., 1985; Cetel and Yen, 1983), suggesting the involvement of endogenous luteinizing hormone releasing hormone (LHRH) in PRL secretion. A recent in vitro study revealed that LHRH stimulates the secretion of PRL in the presence of gonadotrophs, thus implicating the paracrine action of gonadotrophs, on lactotrophs (Denef and Andries, 1983).

In the present study, we investigated

Received October 22, 1987 the acute effect of LHRH on the release of PRL to obtain some insight in the functional communication between gonadotrophs and lactotrophs.

\section{Materials and Methods}

Fifty-four women ranging in age from 16 to 42 were studied. The group comprised 12 women with normal ovulatory cycles and 42 with various menstrual disorders, including 9 with anovulatory cycles, 8 with oligomenorrhea, one with primary amenorrhea, 14 with secondary amenorrhea, 5 with hyperprolactinemia and 5 with ovarian amenorrhea. All subjects were free from medication for the preceding 4 weeks or more.

A bolus intramuscular injection of $100 \mu \mathrm{g}$ of LHRH was given. Blood samples were obtained 
immediately before the injection and at 30 minutes and 60 minutes after. In normal cycling women, LHRH was given at 4 to 7 days after the onset of menstruation. Serum PRL was measured with a RIA kit from Daiichi Radioisotope.

\section{Results}

It is well known that PRL is secreted in a pulsatile fashion. The amplitude and the interval of PRL pulses were reported to be approximately $5 \mathrm{ng} / \mathrm{ml}$ and 90 minutes, respectively. (Masaoka et al., 1986) Therefore, considering that the intraassay variations in PRL are about $8 \%$, it is reasonable to consider a meaningful increase in PRL levels when a $25 \%$ increase in PRL levels are observed at both 30 minutes and 60 minutes after the LHRH injection. Subsequently, we designated this as the "increase" group. The "increase" group was subdivided into 3 subgroups according to the maximum increasing rate : i.e. the first, less than $50 \%$; the second, ranging from $50 \%$ to $100 \%$ and the third, more than $100 \%$. The "decrease" group stands for the cases in which PRL levels decreased by more than $25 \%$ of the initial concentration at both 30 minutes and 60 minutes after the LHRH injection. The remainder was defined as the "no change" group. The number of cases in each group
Table 1. Changes in Prolaction Levels after LHRH Administration

\begin{tabular}{lr}
\hline $\begin{array}{l}\text { Changes in Prolaction } \\
\text { Levels }\end{array}$ & $\begin{array}{c}\text { Number of } \\
\text { Cases (\%) }\end{array}$ \\
\hline Decrease $(\geqq 25 \%)$ & $7(13.0)$ \\
No change & $32(59.3)$ \\
Increase $(\geqq 25 \%)$ & $15(27.8)$ \\
$25 \% \leqq$ rate of increase $<50 \%$ & 4 \\
$50 \% \leqq$ rate of increase $<100 \%$ & 4 \\
Rate of increase $\geqq 100 \%$ & 7 \\
\hline
\end{tabular}

is as follows: the "decrease" group, 7 cases, which accounts for $13.0 \%$ of total cases, the "no change" group, 32 cases $(59.3 \%)$ and the "increase" group, 15 casef $(27.8 \%)$. (Table 1)

Table 2 shows the relationship between the various menstrual disorders and the changes in the PRL concentration following LHRH injection. There seemed to be no apparent tendency of PRL response among them.

It is of interest to see the changes in PRL levels with respect to basal LH concentrations. The data not presented here showed that the degree of changes in PRL levels were not significantly correlated with basal LH concentrations.

Furthermore, we examined whether or not there was any correlation between the changes in PRL and LH levels after LHRH administration, but were not able to detect

Table 2. Changes in Prolactin Levels in Women with Various Menstrual Disorder

\begin{tabular}{|c|c|c|c|c|c|c|}
\hline Menstrual Condition & Decrease & $\begin{array}{l}\text { Changes in } \\
\text { No change }\end{array}$ & $\begin{array}{c}\text { Prolactin Leve } \\
\text { Increase } \\
(25 \%-50 \%)\end{array}$ & $\begin{array}{l}\text { Increase } \\
(50 \%-100 \%)\end{array}$ & $\begin{array}{l}\text { Increase } \\
(\geqq 100 \%)\end{array}$ & Total \\
\hline Normal cycle & 1 & 9 & 1 & 0 & 1 & 12 \\
\hline Anovulatory cycle & 2 & 4 & 0 & 1 & 2 & 9 \\
\hline Oligomenorrhea & 1 & 5 & 1 & 0 & 1 & 8 \\
\hline Primary amenorrhea & 0 & 0 & 0 & 1 & 0 & 1 \\
\hline Secondary amenorrhea $\mathbf{I}^{\circ}$ & 0 & 0 & 1 & 0 & 0 & 1 \\
\hline Secondary amenorrhea $\mathrm{II}^{\circ}$ & 0 & 9 & 1 & 2 & 2 & 14 \\
\hline $\begin{array}{l}\text { Hyperprolactinemia } \\
\qquad(P R L \geqq 30 \mathrm{ng} / \mathrm{ml})\end{array}$ & 3 & 2 & 0 & 0 & 0 & 5 \\
\hline Ovarian amenorrhea & 0 & 3 & 0 & 0 & 1 & 4 \\
\hline
\end{tabular}


Table 3. Changes in Prolactin Levels after LHRH Administration with Respect to Basal Prolactin Levels

\begin{tabular}{|c|c|}
\hline Changes in Prolactin Levels & $\begin{array}{l}\text { Basal Prolactin Leqels } \\
\quad<20 \\
(\mathrm{ng} / \mathrm{ml})\end{array}$ \\
\hline Decrease & 0 \\
\hline No change & 24 \\
\hline Increase $(25 \%-50 \%)$ & 0 \\
\hline Increase $(50 \%-100 \%)$ & 0 \\
\hline Increase $(\geqq 100 \%)$ & 1 \\
\hline Total & 38 \\
\hline
\end{tabular}

any noticeable correlation between the response of the two hormones to LHRH.

Interestingly, the PRL response to LHRH seemed to be related to the basal PRL concentration. (Table 3) In cases with PRL levels being $20 \mathrm{ng} / \mathrm{ml}$ or more, LHRH decreased PRL levels in 7 cases out of 16 . On the other hand, in cases with PRL levels less than $20 \mathrm{ng} / \mathrm{ml}$, LHRH failed to decrease PRL levels in any of the cases tested but it increased PRL levels in 14 out of 38. This differential modality of PRL response to LHRH was shown to be of statistical significance by using the $\chi^{2}$ test. $(\mathrm{p}<0.01)$

\section{Discussion}

In the present study, it was demonstrated that LHRH influences the release of PRL. Moreover, the effect of LHRH was shown to be dependent upon the basal PRL concentration, i. e. positively in normoprolactinemia and negatively in hyperprolactinemia.

It was documented that LHRH elicits a prompt significant release of PRL in certain anovulatory women with slightly elevated PRL levels ( $>20 \mathrm{ng} / \mathrm{ml}$ ), whereas it tends to decrease PRL levels in apparent hyperprolactinemic anovulatory women. (Giampietro et al., 1979) In another report, the increase in PRL caused by LHRH was observed in normal cycling women and hypogonadal women whose PRL levels were normal or slightly high. (Yen et al., 1980) Taken together, it appears that LHRH increases PRL release in normoprolactinemic conditions while it exhibits the opposite effect of PRL release under hyperplolactinemic circumstances.

The LHRH action on PRL release seems to have no relation with the estradiol concentration, (data not presented) suggesting that the action of LHRH is not mediated by the ovary. Other evidence shows that the administration of anti-LHRH serum lowers the serum levels of PRL elevated by haloperidol in ovariectomized rats. (Debeljuk et al., 1985) From these observations, we infer that LHRH may act directly upon either the hypothalamus or the pituitary gland to modulate the release of PRL.

The way in which LHRH alters the PRL concentration remains to be elucidated. A recent study by Denef and Andries (1983) showed that LHRH enhances the PRL release by lactotrophs in the presence of gonadotrophs in vitro, suggestive of a paracrine action of gonadotrophs on lactotrophs. Therefore, it is likely that LHRH acts upon gonadotrophs to release gonadotropin and other unknown substances which in turn cause lactotrophs to release PRL.

Another possible explanation is the mechanism involving dopamine, a common regulator of gonadotropin and PRL. Morphologically, the LHRH secretory system 
is closely associated with the dopaminergic system by axo-axonic contact, suggesting a functional interplay between the two system. Quigley et al. (1979) reported that a suppressed gonadotropin concentration in hyperprolactinemic women is caused by increased dopamine tonus. Inversely, acute elevation of LHRH following exogenous administration of LHRH may produce an inhibition of dopamine release since LHRH and dopamine are considered to be influenced by each other. This may explain the observed positive effect of LHRH on PPL release. On the other hand, LHRH tends to decrease PRL levels in hyperprolactinemic women. This inhibitory effect of LHRH may reflect the pathophysiology underlying abnormal PRL secretion. Further investigation is needed to understand the differential effect of LHRH on the release of PRL.

Clinically, simultaneous injection of LHRH and TRH is employed in certain instances to evaluate the pituitary reserve of gonadotropin and PRL respectively in women with menstrual disorders. In considering the present results, LHRH and TRH should be given separately when examining the function of the anterior pituitary gland.

\section{References}

Bäckström, C. T., A. S. McNeilly, R. M. Leask and D. T. Baird (1982). Pulsatile secretion of LH, FSH, prolactin, oestradiol and progesterone during the human menstrual cycle. Clin. Endocrinol. (Oxf) 17, 29-42.
Braund, W., D. C. Roeger and S. J. Judd (1984). Synchronous secretion of luteinizing hormone and prolactin in the human luteal phase: neuroendocrine mechanisms. J. Clin. Endocrinol. Metab. 58, 293-297.

Cetel, N. S., M. E. Quigley and S. S. C. Yen (1985). Naloxone-induced prolactin secretion in women: evidence against a direct prolactinstimulating effect of endogenous opioids. $J$. Clin. Endocrinol. Metab. 60, 191-196.

Cetel N. S. and S. S. C. Yen (1983). Concomitant pulsatile release of prolactin and luteinizing hormone in hypogonadal women. J. Clin. Endocrinol. Metab. 56, 1313-1315.

Debeljuk, L., I. T. Aleman and A. V. Schally (1985). Antiserum to LH-RH blocks haloperidol-induced hyperprolactinemia in female rats. Neuroendocrinol 40, 185-187.

Denef, C. and M. Andries (1983). Evidence for paracrine interaction between gonadotrophs and lactotrophs in pituitary cell aggregates. Endocrinol. 112, 813-822.

Giampietro, O., G. Moggi, R. Chisci, A. Coluccia, A. D. Luche, N. Simonini and I. Brunori (1979). Unusual prolactin response to luteinizing hormone releasing hormone in some anovulatory women. J. Clin. Endocrinol. Metab. 49, 141-143.

Masaoka, K., M. Kitazawa, T. Niibe and T. Kumasaka (1986). Pulsatile secretion of prolactin during the human menstrual cycle and its neuroendocrine modulators. (in Japanese) Clin. Endocrinol. 34, 185-192.

Quigley, M. E., S. J. Judd, G. B. Gilliland and S. S. C. Yen (1979). Effects of dopamine antagonist on the release of gonadotropin and prolactin in normal women and women with hyperprolactinemic anovulation. J. Clin. Endocrinol. Metab. 48, 718-720.

Yen, S. S. C., J. D. Hoff, B. L. Lasley, R. F. Casper and K. Sheehan (1980). Induction of prolactin release by LRF and LRF-agonist. Life Sci. 26, 1963-1967. 